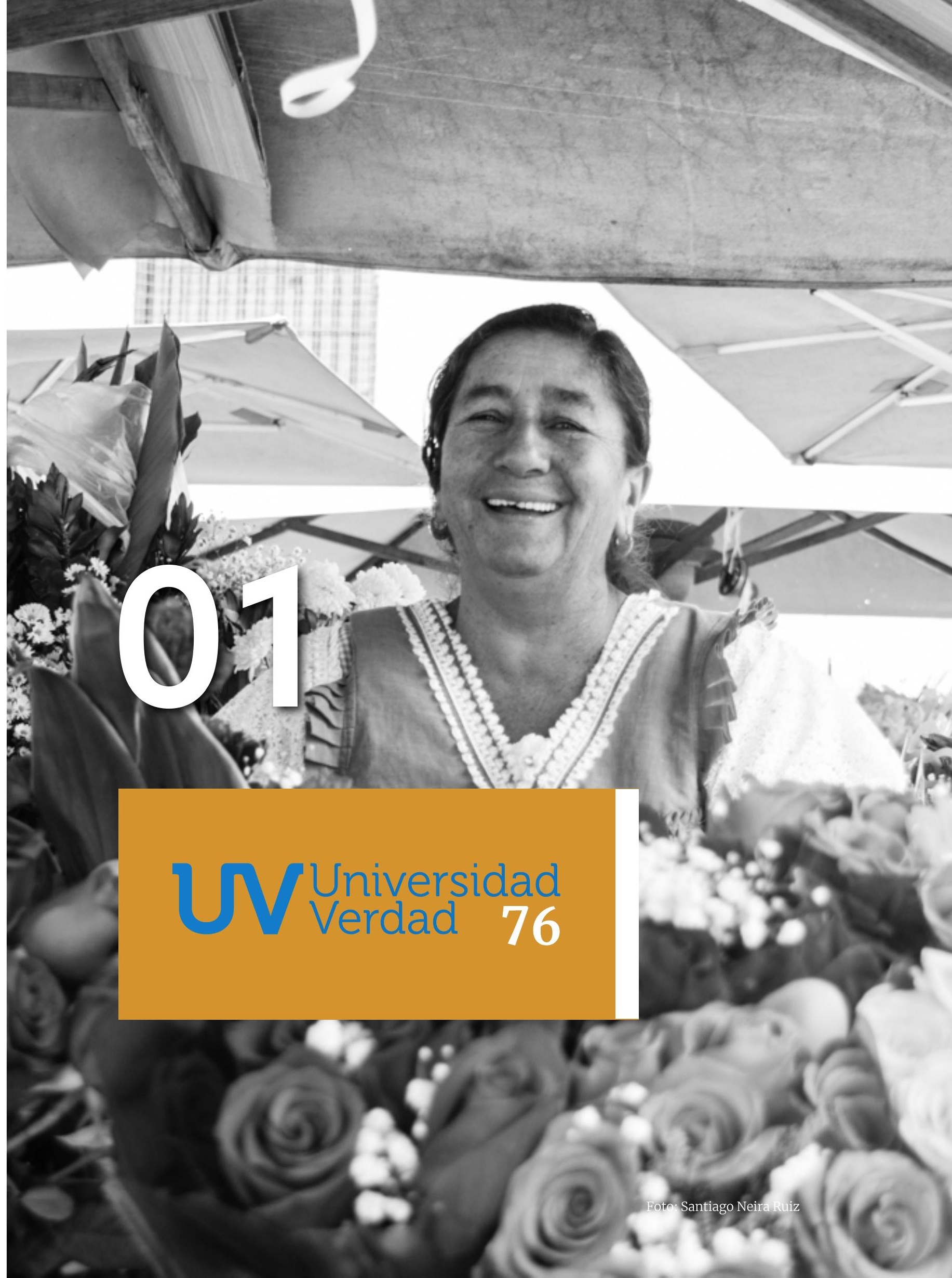




\section{EL CENTRO HISTÓRICO DE CUENCA: CONSERVACIÓNY TURISMO FRENTE A LAS DINÁMICAS POPULARES}

\section{The Historic Center of Cuenca: conservation and tourism in front of popular dynamics}

iD Arq. Natasha Cabrera Jara, $\mathrm{PhD}(\mathrm{c})$. Docente e investigadora de la Facultad de Diseño, Arquitectura y Artes. Universidad del Azuay.UDA. (Ecuador) (necabrera@uazuay.edu.ec) (https://orcid.org/0000-0002-1469-2349)

\section{Resumen}

Existe una noción de lo patrimonial ampliamente ligada a lo material, monumental y arquitectónico. Lo que ha focalizado las políticas de conservación en la preservación de sus componentes físicos desde una lógica de lo estático, que ha afectado el dinamismo urbano presente en las prácticas cotidianas ligadas a lo popular y la comunidad. La investigación que se propone busca aportar en el debate sobre los efectos que las políticas de conservación en las áreas patrimoniales en ciudades latinoamericanas han ejercido sobre las prácticas populares y la comunidad, y su relación con la inserción del turismo. Con este fin se presentan los resultados de las primeras etapas de la investigación que toma a Cuenca como caso de estudio. Dichas etapas corresponden a la caracterización del área patrimonial cuencana y al análisis de los instrumentos de planificación relacionados. Los resultados señalan que estos instrumentos se centran en la conservación de las características físicas del patrimonio, la restauración de su arquitectura relevante y la regeneración del espacio público, que en ocasiones incluye la restricción de usos populares y de manifestaciones artísticas. El turismo aparece además como un agente promotor de la conservación y de una estética específica sujeta a la mercadotecnia turística internacional.

\section{Abstract}

There is a notion of heritage widely linked to notion of material, monumental and architectural. That has focused conservation policies on the preservation of its physical components from a logic of the static, which has affected the urban dynamism present in daily practices linked to the popular and the community. The proposed research seeks to contribute to the debate on the effects that conservation policies in heritage areas in Latin American cities have had on popular practices and the community, and its relationship with the insertion of tourism. To this end, the results of the first stages of the research that takes Cuenca as a case study are presented. These stages correspond to the characterization of the Cuenca heritage area and the analysis of the related planning instruments. The results indicate that these instruments focus on the preservation of the physical characteristics of the heritage, the restoration of its relevant architecture and the regeneration of public space, which sometimes includes the restriction of popular uses and artistic manifestations. Tourism also appears as an agent promoting conservation and a specific aesthetic related to international tourism marketing.

\section{Palabras clave}

Patrimonio urbano, conservación, prácticas populares, desplazamiento.

\section{Keywords}

Urban heritage, conservation, popular practices, displacement. 
1.

\section{Lo material e inmaterial en la defini- ción de patrimonio}

El abordaje de lo patrimonial a partir de su valor excepcional ha sido ampliamente extendido, en particular por entidades como la UNESCO y el ICOMOS (International Council on Monuments and Sites). Este valor hace referencia a "un mínimo de singularidad, para el cual no hay sustituto" (Waldenfels, 2009, p. 172). Justamente en esta condición excepcional e irremplazable se fundamenta la importancia de conservar el patrimonio de las naciones (UNESCO, 2018). Con este fin se han generado acuerdos, políticas e instituciones internacionales y nacionales que procuran el legado de los bienes patrimoniales a las futuras generaciones.

Como paso inicial, la conservación del patrimonio ha demandado la elaboración de inventarios de bienes en los cuales se identifican y describen sus valores excepcionales, estado y riesgos, para su posterior catalogación en función de su valor y vulnerabilidad (Osorio, 2012; Pedersen, 2005). Bajo esta práctica se han creado una serie de listados e inventarios locales, nacionales e internacionales como el Inventario de Bienes del Sistema de Información del Patrimonio Cultural Ecuatoriano (SIPCE), o la Lista del Patrimonio Mundial de la UNESCO.

Esta aproximación a lo patrimonial estuvo centrada desde un principio en la valoración de lo monumental, de lo material. De tal modo que aún en 2014, la UNESCO definía al patrimonio cultural en referencia a aquellos monumentos, obras arquitectónicas, de escultura o pintura, grupos de construcciones y lugares que presentan un valor excepcional dentro de la historia, el arte o la ciencia (UNESCO, 2014). El vínculo patrimonio cultural-patrimonio material se evidencia en las diversas cartas internacionales destinadas a la puesta en valor y salvaguarda del patrimonio, como: Carta de Atenas de 1931, Carta de Venecia de 1964, Carta de Quito de 1967, Carta de Veracruz de 1992, Carta de Cracovia de 2000, Memorándum de Viena de 2005 (ICOMOS, 2015); en las cuales los valores del patrimonio cultural se definen en función de sus características materiales y los del patrimonio urbano en relación con el entorno construido, arquitectura y bienes muebles. Estos documentos internacionales se centran en la conservación de las características materiales del entorno construido: monumentos, sitios, arquitectura.

En las dos últimas décadas se han observado serios cuestionamientos sobre la comprensión de lo patrimonial a partir de sus características físicas y de sus valores excepcionales como elementos estáticos, netamente monumentales y arquitectónicos, y se ha planteado una nueva categoría que busca reposicionar la importancia de lo inmaterial y la comunidad. Esta categoría, definida como patrimonio inmaterial o patrimonio intangible, busca integrar al concepto europeo de patrimonio cultural otros componentes fundamentales como los usos, las representaciones, las expresiones y los conocimientos de diversos grupos humanos (UNESCO, 2011). En apego a estas reflexiones el patrimonio urbano queda ligado al patrimonio intangible, que es parte esencial en la vida cotidiana de la ciudad.

En este sentido, ya en el siglo pasado autores como Lefevre $(1969,1972)$ resaltaron el poder de transformación ejercido por los ciudadanos en el espacio urbano, por encima de sus características territoriales, físicas y demográficas. Este autor propuso superar el entendimiento del espacio urbano como contenedor de edificios, población y actividades productivas. Su planteamiento remarcó la condición dinámica y heterogénea del espacio urbano, donde las actividades cotidianas dotan al mismo de significado.

\subsection{La conservación de lo monumental y el despla- zamiento de lo modesto.}

Pese a estos intentos, la presión de integrarse y permanecer en la Lista de Patrimonio Mundial lleva a los gobiernos nacionales y locales a orientar la conservación de su patrimonio edificado basándose en estándares internacionales, que, finalmente, minimizan a la comunidad que habita dichos espacios (De la Calle, 2002). En América Latina, los estudios sobre este fenómeno tienen como referente a la investigación de Jones y Varley de 1999, que analizó los proyectos de conservación en Puebla, ciudad co- 
lonial de México. El estudio puso en debate el papel del turismo en la conservación de áreas urbanas patrimoniales latinoamericanas y lo identificó como el actor principal de sus procesos de 'rehabilitación' y 'regeneración', que originaron desplazamientos de población, usos y prácticas culturales (Janoschka, Sequera \& Salinas, 2013).

De manera posterior, autores como Navarrete (2017) señalan que la promoción del turismo en ciudades patrimoniales de América Latina ha fomentado la conservación del patrimonio edificado con el consecuente "cambio de uso de suelo habitacional o mixto con actividades comerciales tradicionales a un uso comercial y de servicios con vocación internacional" (p. 65). De la Calle (2002) afirma que las políticas de protección del patrimonio edificado junto a las de inserción del turismo han afectado prácticas culturales cotidianas relacionadas con lo popular. En este sentido, Mathus (2017) explica cómo en el Barrio Lastarria en Santiago de Chile este fenómeno ha tenido lugar en torno a una "lógica de comunidad purificada [...] que dificulta el arraigo y la construcción de un proyecto de futuro territorial" (p. 182). Mientras Díaz (2015) remarca el desplazamiento de sectores populares, junto a sus prácticas y usos, tras la regeneración de zonas históricas y patrimoniales en Ciudad de México, Buenos Aires, Lima y Cartagena de Indias, debido al incremento de los costos derivados de las intervenciones y de la llegada del turismo, lo que "dificulta la permanencia de los residentes tradicionales" (p. 20).

La revisión de estos casos muestra cómo las políticas de conservación del patrimonio urbano ligadas al desarrollo turístico, han promovido intervenciones de regeneración, rehabilitación y restauración sobre el patrimonio material: arquitectura, monumentos y espacio público; que han desplazado a las prácticas populares y la comunidad, relacionadas ambas con un patrimonio intangible más modesto. Para Hiernaux y González (2015), la relación patrimonio-turismo, se ve potenciada por la sociedad del espectáculo, que alimenta a su vez al 'urbanismo escenográfico', que se centra en la reproducción de un cierto tipo de imagen (Manrique, 2013). Esta 'imagen', a la que se refiere Pallasma (2014), resulta de la "actual producción en serie de imágenes mercantilizadas y neutralizadoras, que imaginan en nuestro nombre" (p. 7) y que resaltan las diversas maneras en las que hoy el sentido de la vista predomina en las prácticas culturales. Para este autor "el contundente imaginario contemporáneo crea su propia realidad, y esta es más 'real' que los mundos físicos y humanos existentes" (p. 15).

\section{2.}

\section{Cuenca como caso de estudio}

En este contexto Cuenca aparece como un caso de estudio pertinente, no solo porque cuenta con una de las dos áreas urbanas declaradas Patrimonio Cultural de la Humanidad por la UNESCO en el Ecuador', sino debido a una serie de proyectos de conservación y regeneración llevados a cabo en su área patrimonial y su entorno inmediato, con el fin de volverlos más atractivos para el turista. Esta situación ha modificado su morfología y tejido social, ha promovido el desplazamiento de habitantes y prácticas populares (Marulanda y Martí, 2019) y ha derivado en su éxito como destino turístico, reflejado en múltiples premios y reconocimientos internacionales como la obtención de los dos primeros lugares entre 2010 y 2016 en el listado mundial de las mejores ciudades para jubilados extranjeros (García et ál., 2017), la inclusión en 2011 en la lista de las 50 mejores ciudades históricas del mundo de la revista National Geographic (Zibell, 2012), y la conquista del Oscar del Turismo entre 2017 y 2019 como mejor destino en Sudamérica para estancias cortas (World Travel Awards, 2019).

En consecuencia, esta investigación propone al centro histórico de Cuenca como caso de estudio (Figura 1). Con el fin de contribuir al debate sobre las lógicas de conservación del patrimonio urbano en América Latina, su relación con el desarrollo del turismo y los efectos sobre los usos y las prácticas populares, ligadas a un patrimonio intangible más modesto.

1 Quito, capital de Ecuador, obtuvo la declaratoria en 1978 sobre un total de 375 hectáreas de su centro histórico, considerado "el mejor conservado y menos alterado de toda América Latina" (UNESCO, 2017a). El Centro Histórico de Cuenca, ciudad intermedia más importante del país, obtuvo la declaratoria a finales de 1999 sobre un total de 224 hectáreas debido a la aplicación y la conservación de "la estricta normativa urbanística promulgada (...) por el emperador Carlos V" (UNESCO, 2017b). 


\section{Figura 1}

\section{Centro Histórico de Cuenca}
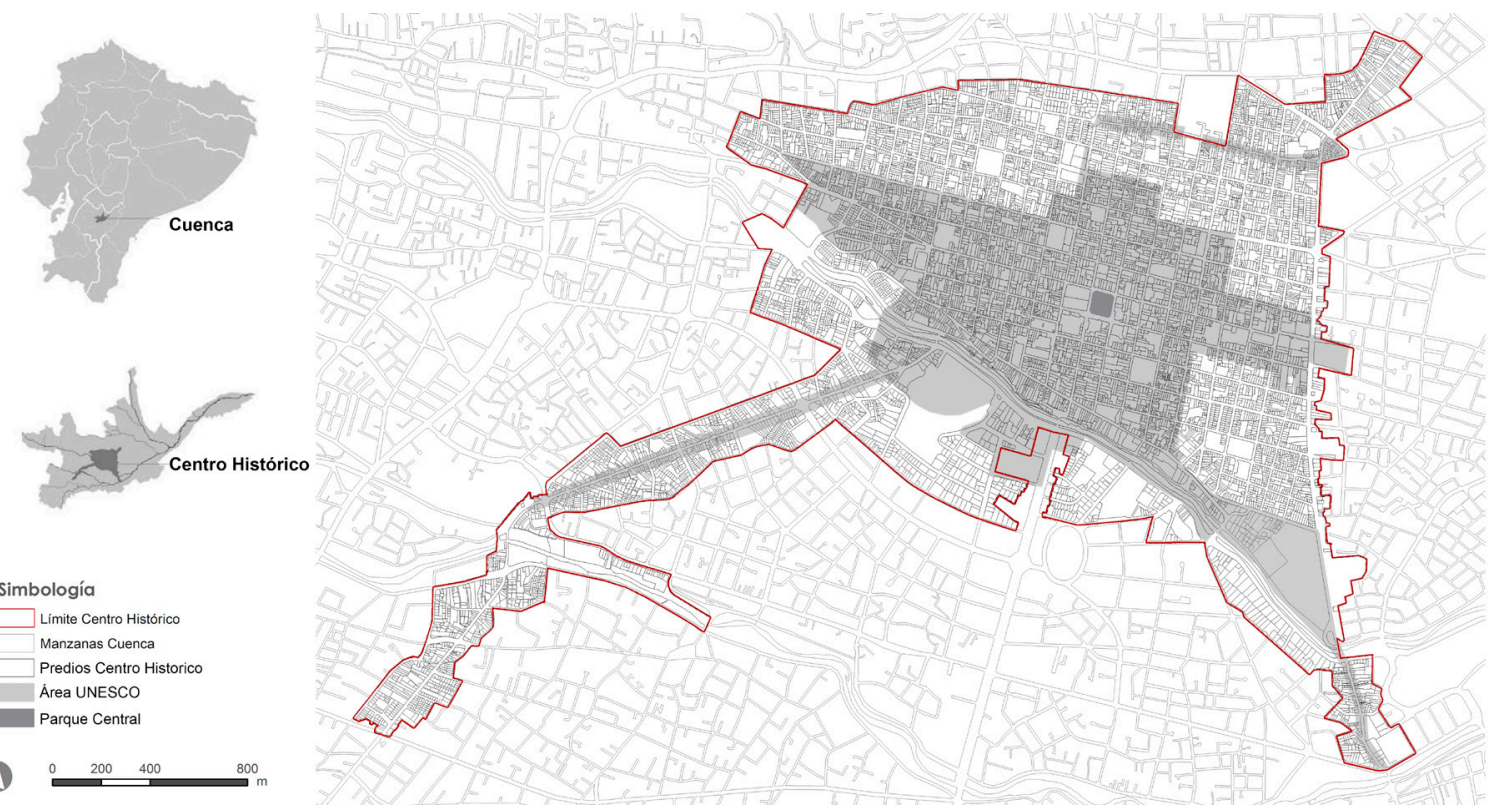

Simbología

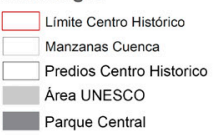

$1 \quad \begin{array}{rrrr}0 \quad 200 & 400 \quad 800 \\ \end{array}$

Nota: Imagen elaborada en ArcGIS

\subsection{Metodología}

El método empleado presenta un carácter mixto dividido en cuatro etapas metodológicas:

Etapa 1.Caracterización del caso de estudio. En esta etapa los datos se obtienen de la revisión documental y cartográfica, mapeo y recorrido in situ, que se sistematizan para la elaboración de un informe de caracterización.

Etapa 2. Fichaje de planes implementados. Cuyos datos se recogen de la revisión de los documentos oficiales disponibles, que se sistematizan en una ficha tipo (Tabla 1) y se analizan mediante codificación temática. 


\section{Tabla 1}

Ficha para sistematización de planes

\begin{tabular}{|l|}
\hline Ficha No PL_ooo \\
\hline Nombre del instrumento de planificación \\
\hline Área de actuación \\
\hline Fecha de elaboración \\
\hline Fecha de aprobación/estado \\
\hline Autores/entidad gestora \\
\hline Duración \\
\hline Descripción \\
\hline Visión/enfoque/datos sobre patrimonio \\
\hline Visión/enfoque/datos sobre patrimonio material \\
\hline Visión/enfoque/datos sobre patrimonio inmaterial \\
\hline $\begin{array}{l}\text { Visión/enfoque/datos sobre turismo a escala de ciu- } \\
\text { dad/provincia }\end{array}$ \\
\hline $\begin{array}{l}\text { Visión/enfoque/datos sobre turismo en el área patri- } \\
\text { monial }\end{array}$ \\
\hline $\begin{array}{l}\text { Planes, programas y proyectos derivados (relaciona- } \\
\text { dos con patrimonio y/o turismo) }\end{array}$ \\
\hline \begin{tabular}{l} 
Observaciones \\
\hline Referencias bibliográficas (APA 6ta edición)
\end{tabular} \\
\hline
\end{tabular}

Etapa 3. Estudio de los proyectos de regeneración y conservación ejecutados. En este caso se obtienen datos sobre los diferentes proyectos llevados a cabo en el área de estudio, a partir de la declaratoria de la UNESCO en 1999, hasta 2019. Estos datos se recogen de la revisión documental y de cartografía, levantamiento in situ y entrevistas semiestructuradas, y se sistematizan en una ficha tipo que comprende datos alfanuméricos y gráficos, que posteriormente se analizan mediante codificación temática y análisis espacial.

Etapa 4. Análisis espacial del desplazamiento de usos y prácticas populares. A partir de la información sistematizada en las fichas de proyecto se georreferencian los datos referidos a los desplazamientos y sus efectos para el respectivo análisis espacial.
Este artículo presenta resultados preliminares de la investigación, referidos a las dos primeras etapas metodológicas. Para la caracterización del caso de estudio se revisaron documentos y cartografía sobre Cuenca y su área patrimonial, para determinar sus principales características y contextualizar el caso a nivel regional e histórico. Adicionalmente, se analizó material anterior a la declaratoria de la UNESCO utilizado como insumo para su postulación. Se sistematizó la literatura encontrada en una base de datos diseñada con este fin y se archivaron las imágenes (fotografías, dibujos y mapas) más representativas. Se elaboraron mapas y se realizaron distintos recorridos en el área de estudio y en su contexto inmediato.

Para el fichaje de planes implementados se revisaron todos los instrumentos de planificación que incidieron en el área patrimonial de la ciudad y se sistematizaron mediante una ficha que recogió datos técnicos generales (área y fecha de actuación, alcance, autores, duración) e información detallada sobre el tratamiento tanto del patrimonio tangible e intangible como del turismo, y sobre las políticas, las estrategias y los proyectos planteados. La información recogida en las fichas fue analizada mediante codificación temática para la elaboración de mapas conceptuales y árboles de conceptos.

\section{3.}

\section{Resultados}

A continuación, se muestran los resultados preliminares de investigación, de las etapas metodológicas 1 y 2 referidas a la caracterización del caso de estudio y al fichaje de planes, respectivamente. La primera se presenta como El Centro Histórico de Cuenca, Patrimonio Cultural de la Humanidad y la segunda como Planes implementados.

\subsection{El Centro Histórico de Cuenca, Patrimonio Cul- tural de la Humanidad}

El Plan de Desarrollo Urbano del Área Patrimonio de Cuenca (PDUAMC) delimitó, en 1982, el centro histórico, resaltando el conjunto de sus iglesias y conventos coloniales y una arquitectura civil del siglo XIX como unidad de valor patrimonial, lo que se concretó en su declaratoria como Patrimonio Cultu- 
ral Nacional del mismo año y en la emisión de una ordenanza especial para la protección de las edificaciones patrimoniales. Este plan incorporó al imaginario cuencano la noción de patrimonio y planteó la necesidad de preservarlo.

Con estos antecedentes y en consideración al Plan Regional de Desarrollo Turístico de 1996 -que resaltaba el valor paisajístico del centro histórico-, la alcaldía del arquitecto Fernando Cordero Cueva (1996-2000) asumió como hoja de ruta el reconocimiento internacional de los valores patrimoniales de Cuenca. En 1998 en un esfuerzo conjunto con la Universidad de Cuenca se elaboró el expediente para la postulación a la Lista de Patrimonio de la Humanidad de la UNESCO (Cardoso, 2017).

Dicho expediente resaltó, como valores excepcionales del Centro Histórico de Cuenca, las siguientes (Figuras 2 y 3 ): ...su capacidad de ofrecernos un conjunto histórico, urbano, arquitectónico y paisajístico único, incluso si es observado en un contexto latinoamericano... es una de las más fidedignas y concretas realizaciones urbanas de "entroterra", desarrolladas a partir de las disposiciones españolas... guarda una gran coherencia con su historia. De corazón colonial, de tecnología y maestrías mestizas, y de piel que parecería ser el resultado de un remoto reflejo de las imágenes de la arquitectura europea... Su relación con la naturaleza es una constante a lo largo de su historia, el diálogo de la ciudad con el cordón montañoso que la circunda... El Barranco del Tomebamba el que sin duda queda guardado en la memoria colectiva, como una imagen altamente representativa de esta ciudad. (Ilustre Municipalidad de Cuenca, 1998, pp. 48-49)

\section{Figura 2}

\section{Centro Histórico de Cuenca: en primer plano la Plaza San Francisco}

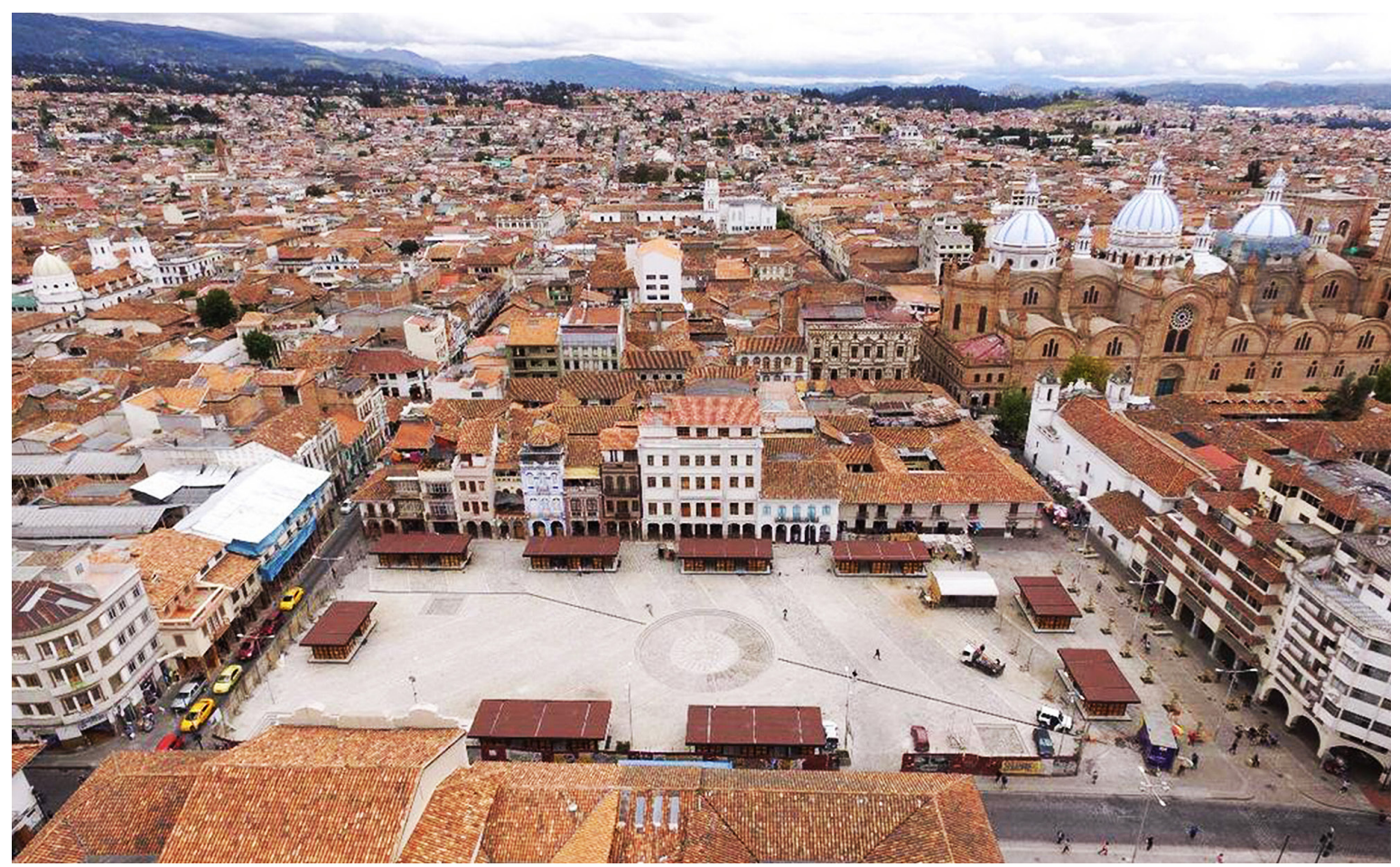

Fuente: Elasterix, 2019².

2 Elasterix. (2019). Plaza de San Francisco. Cuenca, Ecuador: GAD Municipal de Cuenca. 


\section{Figura 3}

Postal del Barranco y el Río Tomebamba

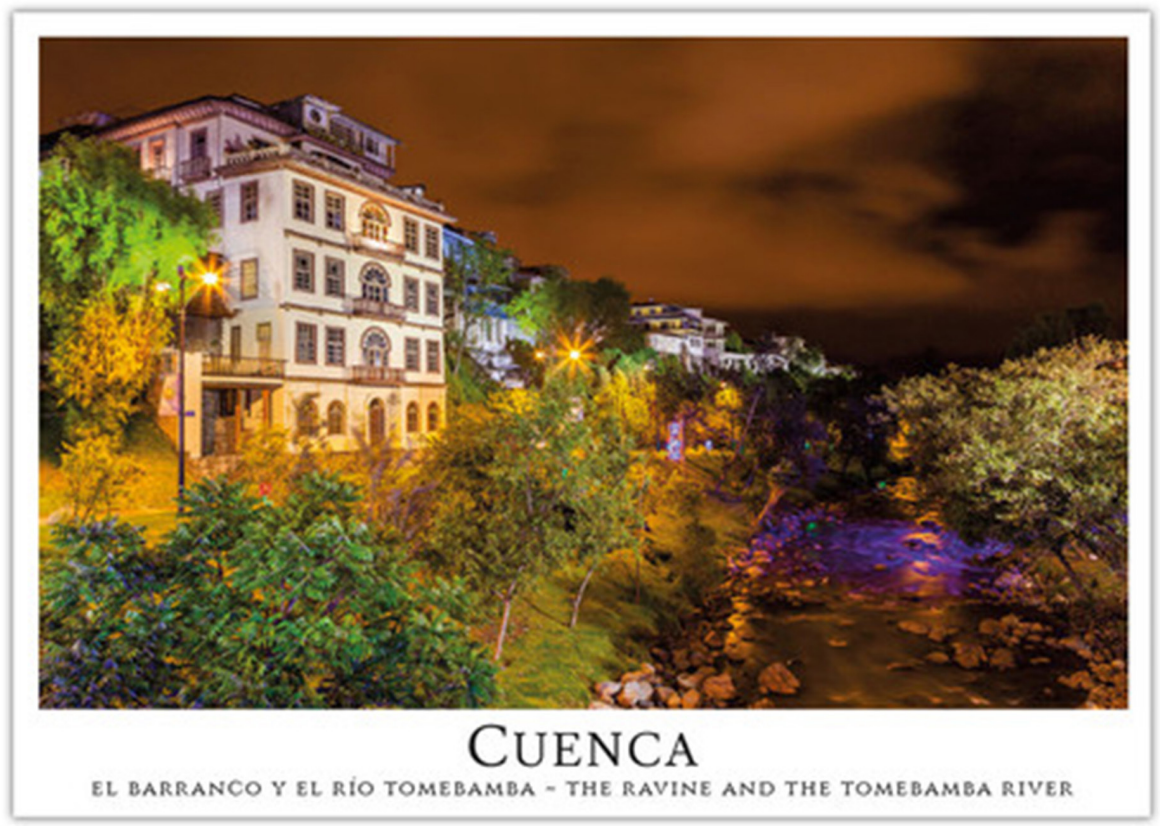

Fuente: Balarezo, 2017³.

La postulación fue aceptada el 1 de diciembre de 1999 por el Comité de Patrimonio Mundial de la UNESCO por las siguientes razones:

Criterio ii: Cuenca ilustra la perfecta implementación de los principios de planificación urbana del Renacimiento en las Américas.

Criterio iv: La fusión exitosa de las diferentes sociedades y culturas de América Latina está simbolizada de manera sorprendente por el trazado y el paisaje urbano de Cuenca.

Criterio v: Cuenca es un ejemplo sobresaliente de una ciudad colonial española planeada en el interior. (Cardoso, 2017, pp. 20-21)

La declaratoria de la UNESCO significó el reconocimiento internacional de los valores excepcionales del área patrimonial cuencana y demandó la ejecución de acciones encaminadas a su protección y puesta en valor.

\subsection{Planes implementados}

Se analizaron un total de nueve planes, todos con incidencia en el centro histórico cuencano, en temas referidos a su patrimonio y conservación. En la tabla siguiente (Tabla 2) se muestra cada instrumento de planificación revisado con su fecha de aprobación o elaboración, según el caso, sus postulados sobre lo patrimonial y los programas, estrategias y/o acciones propuestas. Esto permite entender el enfoque de cada plan y su concepción de lo patrimonial y sus valores.

3 Balarezo, K. (2017). El Barranco y el Río Tomebamba. Disponible en https://www.vvsschools.org/Page/3608 


\section{Tabla 2}

Planes y programas analizados

\begin{tabular}{|c|c|c|c|}
\hline Nombre del Plan & Año & Postulados & Programas/estrategias/acciones \\
\hline $\begin{array}{l}\text { Anteproyecto del Plan Regu- } \\
\text { lador }\end{array}$ & 1947 & $\begin{array}{l}\text { Ausencia de una noción patri- } \\
\text { monial. }\end{array}$ & $\begin{array}{l}\text {-Delimitación del centro histórico } \\
\text { como zona de gobierno, bancaria y } \\
\text { comercial. }\end{array}$ \\
\hline $\begin{array}{l}\text { Plan Director de Desarrollo } \\
\text { Urbano }\end{array}$ & 1971 & $\begin{array}{l}\text { Ausencia de una noción patri- } \\
\text { monial. }\end{array}$ & $\begin{array}{l}\text {-División del centro histórico en centro } \\
\text { administrativo y habitacional (al borde). }\end{array}$ \\
\hline $\begin{array}{l}\text { Plan de Desarrollo Urbano del } \\
\text { Área Metropolitana de Cuen- } \\
\text { ca (PDUAMC) }\end{array}$ & 1982 & $\begin{array}{l}\text { Centro histórico como unidad de } \\
\text { valor patrimonial. } \\
\text { Plantea la preservación y conser- } \\
\text { vación del área histórica. } \\
\text { Institucionaliza el discurso del pa- } \\
\text { trimonio edificado. }\end{array}$ & $\begin{array}{l}\text {-Descongestión y homogenización } \\
\text { del centro histórico. } \\
\text {-Restricción de usos, ocupación y al- } \\
\text { tura (normativa). } \\
\text {-Jerarquización por zonas y delimita- } \\
\text { ción del área arqueológica. }\end{array}$ \\
\hline \multicolumn{4}{|c|}{ CENTRO HISTÓRICO DECLARADO ‘PATRIMONIO CULTURAL DE LA HUMANIDAD’ POR LA UNESCO, 1999} \\
\hline PDUAMC - Reforma & 2003 & $\begin{array}{l}\text { Promoción del área patrimonial } \\
\text { como destino turístico. } \\
\text { Institucionaliza el concepto de 'le- } \\
\text { gado histórico' }\end{array}$ & $\begin{array}{l}\text {-Creación de la Fundación Municipal } \\
\text { de Turismo (2005). }\end{array}$ \\
\hline $\begin{array}{l}\text { Plan de } \\
\text { miento }\end{array}$ & $\begin{array}{l}2007- \\
2011\end{array}$ & $\begin{array}{l}\text { Política de respeto y protección } \\
\text { del centro histórico. } \\
\text { Promueve el conservacionismo del } \\
\text { patrimonio monumental. }\end{array}$ & $\begin{array}{l}\text { puesta en valor del } \\
\text { lo. }\end{array}$ \\
\hline $\begin{array}{l}\text { Plan Estratégico de Desa- } \\
\text { rrollo Turístico del destino } \\
\text { Cuenca y su área de Influen- } \\
\text { cia }\end{array}$ & 2011 & $\begin{array}{l}\text { Concibe el patrimonio material } \\
\text { como un recurso turístico } \\
\text { Centra el desarrollo turístico en la } \\
\text { zona declarada por la UNESCO }\end{array}$ & $\begin{array}{l}\text {-Planteamiento de nueve estrategias } \\
\text { para el desarrollo del turismo relacio- } \\
\text { nado con áreas patrimoniales. }\end{array}$ \\
\hline $\begin{array}{l}\text { Plan Especia } \\
\text { tórico de Cue }\end{array}$ & $2015^{*}$ & $\begin{array}{l}\text { Profundiza en la política conser- } \\
\text { vacionista de lo material (bienes } \\
\text { muebles e inmuebles) }\end{array}$ & $\begin{array}{l}\text {-Programa para la puesta en valor del } \\
\text { espacio público y el espacio edificado. } \\
\text {-Restricción de usos populares y ma- } \\
\text { nifestaciones artísticas en el espacio } \\
\text { público. } \\
\text {-Revisión y ampliación del inventario } \\
\text { patrimonial y su normativa. }\end{array}$ \\
\hline $\begin{array}{l}\text { Plan de Desarrollo y Ordena- } \\
\text { miento Territorial del Azuay } \\
\text { Actualizado, 2015-2030 }\end{array}$ & 2015 & $\begin{array}{l}\text { Concibe el patrimonio material } \\
\text { como un recurso turístico }\end{array}$ & $\begin{array}{l}\text {-Estrategias para la inserción de las } \\
\text { áreas patrimoniales en el turismo in- } \\
\text { ternacional. }\end{array}$ \\
\hline $\begin{array}{l}\text { Plan de Reactivación del Es- } \\
\text { pacio Público en Cuenca }\end{array}$ & $2016^{*}$ & $\begin{array}{l}\text { Protege el valor histórico-patri- } \\
\text { monial de lo edificado. }\end{array}$ & $\begin{array}{l}\text {-Programa de reactivación del espa- } \\
\text { cio público en el centro histórico. }\end{array}$ \\
\hline
\end{tabular}

*A la fecha estos planes aún no han sido aprobados por el Concejo Cantonal de Cuenca.

Fuente: Barrera, et ál., 2008; Cabrera y Greene, 2018. 
La revisión de los planes permitió identificar que las nociones sobre lo patrimonial han girado en torno a la conservación del patrimonio edificado y se han orientado en la imagen ideal de centro histórico de traza colonial y arquitectura republicana, sin considerar usos y prácticas populares. En general, la política manejada en los instrumentos de planificación posteriores a la declaratoria de la UNESCO ha perseguido la internacionalización del turismo mediante la potenciación de las ventajas competitivas (GAD Provincial del Azuay, 2015, p. 266), para así mejorar la economía local (p. 88), en busca de la sustentabilidad patrimonial (p. 210). A nivel cantonal se han planteado nueve estrategias para desarrollar el turismo (GAD Municipal de Cuenca, 2011), considerando la declaratoria de la UNESCO como "una gran oferta para el desarrollo del sector turístico" (p. 33). Como se señala en el Plan Especial del Centro Histórico de Cuenca (Ilustre Municipalidad de Cuenca, 2009) y el Plan Estratégico de Desarrollo Turístico del destino Cuenca y su área de Influencia (Fundación Municipal Turismo para Cuenca, 2011), la estrategia predominante ha sido la 'regeneración' de los espacios públicos para mejorar el paisaje urbano e incrementar el número de turistas.

\section{Figura 4}

Conjunto de intervenciones en la Plaza Rotary, Centro Comercial Popular, Mercado 9 de Octubre y Plaza Cívica

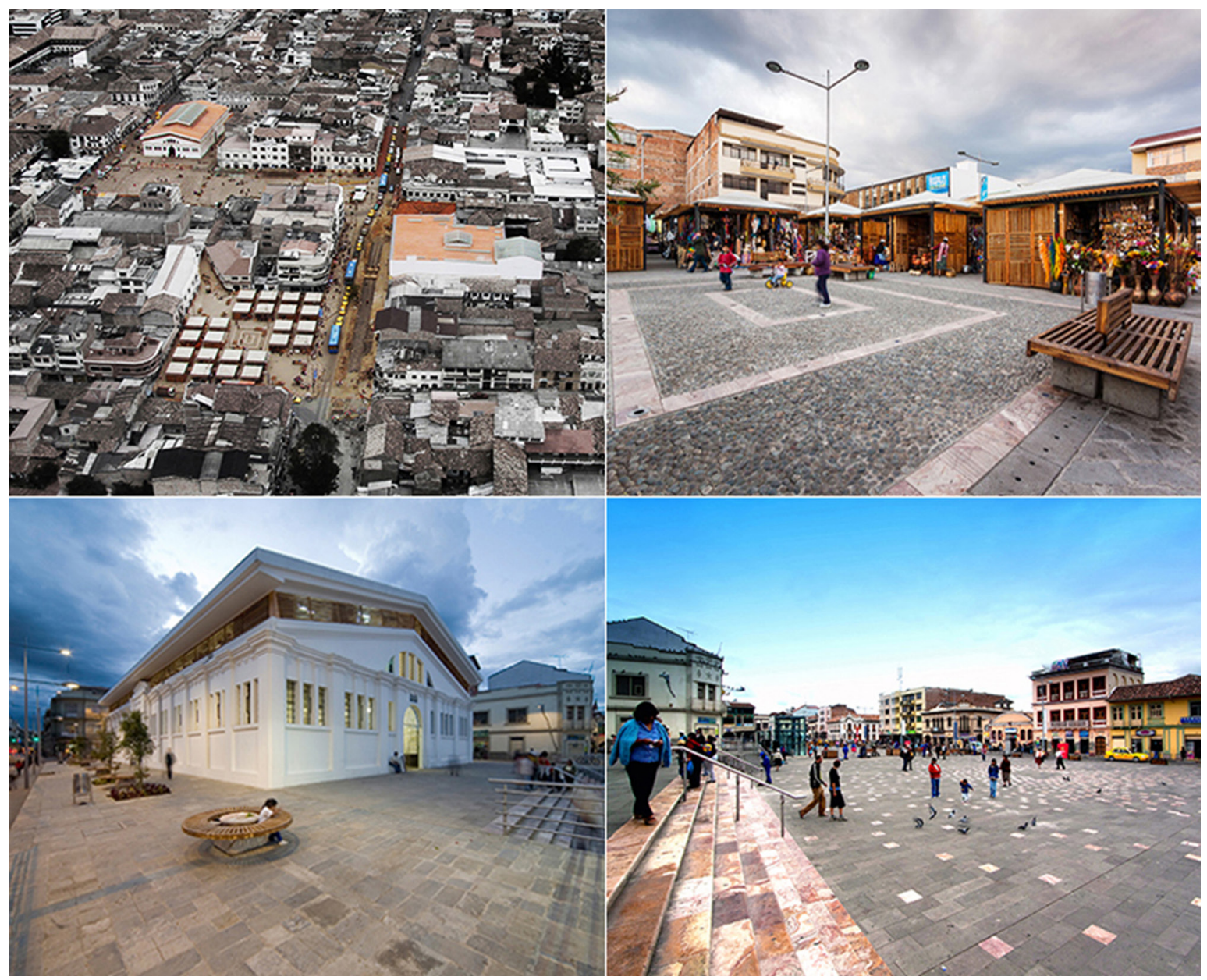

Fuente: Albornoz, 2018. ${ }^{4}$

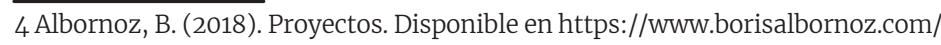


Este enfoque refleja la predominancia de una noción de espacio urbano objetivo, homogéneo, medible y estático, que no ha contemplado las dinámicas cotidianas ni la estética populares, e inclusive plantea su restricción como en el caso del Plan Especial del Centro Histórico de 2015. El interés por promover el desarrollo turístico en el caso cuencano ha tendido a eliminar del área patrimonial aquellos componentes que resultan menos atractivos para el turista, específicamente usos populares y manifestaciones artísticas en el espacio público. Como lo reflejan las intervenciones sobre plazas cercanas a los mercados (Figura 2).

El proyecto que grafica de mejor manera la política manejada en Cuenca es la intervención sobre el Mercado 9 de Octubre, la Plaza Cívica, la Plaza Rotary y el Centro Comercial Popular. En conjunto estos proyectos contemplan la restauración de una edificación patrimonial (el mercado), la regeneración de espacios públicos (las plazas) y la construcción de obra nueva (centro comercial). La calidad de la intervención arquitectónica y de diseño quedó manifestada con la obtención del Premio Latinoamericano de Arquitectura Rogelio Salmona, en la categoría Rehabilitación Urbana en 2016, donde se resaltó su aporte al paisaje histórico urbano y al control del manejo del espacio público. Sin embargo, el comercio ambulante y las prácticas populares como la medicina tradicional y las manifestaciones artísticas populares no fueron contempladas en el proyecto, y hoy se restringe su presencia (Figura 4).

A la fecha, se ha concluido con la recolección de información de la tercera etapa metodológica, en la cual se han identificado 49 proyectos en el espacio público y 22 en edificaciones de uso público (Figura 4). Sin embargo, no se ha iniciado con el proceso de análisis. Estas intervenciones alcanzan las 31,74 hectáreas, que representa el 28,5\% del espacio público total del área patrimonial de Cuenca.

\section{4.}

\section{Discusión y conclusiones}

Los resultados de esta primera etapa de investigación manifiestan la comprensión de lo patrimonial desde sus valores materiales, por lo que los planes revisados se centran en la conservación de lo edificado y lo monumental y la reproducción de un espacio urbano donde los usos comerciales populares son desplazados paulatinamente porque inciden negativamente en el patrimonio y se restringen actividades espontáneas y manifestaciones artísticas. Esta visión no contempla ni lo inmaterial ni a la comunidad, cuya importancia es resaltada por las mismas entidades que han sobrevalorado el patrimonio material, pero que hoy han asumido una postura crítica frente a esta aproximación, aunque aún retórica.

Estos primeros hallazgos muestran que los instrumentos de planificación aplicados en el caso de Cuenca, coinciden con las políticas manejadas en otros casos latinoamericanos en que la sobrevaloración de lo edificado está relacionada con el desarrollo del turismo, en detrimento de otros valores cotidianos vinculados con lo popular y menos pintoresco. En los distintos ejemplos revisados algunos autores describen procesos de desplazamiento y gentrificación drásticos como la limpieza social en el caso de Cartagena de Indias y Ciudad de México (Díaz, 2015) y la construcción de un urbanismo escenográfico (Manrique, 2013). Y aunque las políticas presentes en los planes cuencanos no se refieren directamente a estos procesos, no dan paso a una comprensión del patrimonio desde una noción dinámica, cambiante e inclusiva.

El análisis de los planes valida la construcción de una imagen urbana acorde con las demandas del turismo internacional, de ahí el éxito cuencano en los distintos rankings turísticos, sin embargo, esta estética deja por fuera múltiples manifestaciones relacionadas con lo popular, que en el caso latinoamericano está directamente vinculado a lo indígena. El fomento del turismo como tal no puede ser el eje de la política urbana, sino una de las herramientas que permita el desarrollo local y propicie la cohesión social y la disminución de las grandes desigualdades históricas de las ciudades latinoamericanas. Y esto tiene que ver con un entendimiento del patrimonio y de lo urbano como un ente vivo, dinámico y cotidiano.

Los primeros resultados de esta investigación muestran la importancia de fomentar este debate, de profundizar en los efectos de las políticas de conserva- 
Figura 5

Proyectos de intervención identificados entre 1999 y 2019

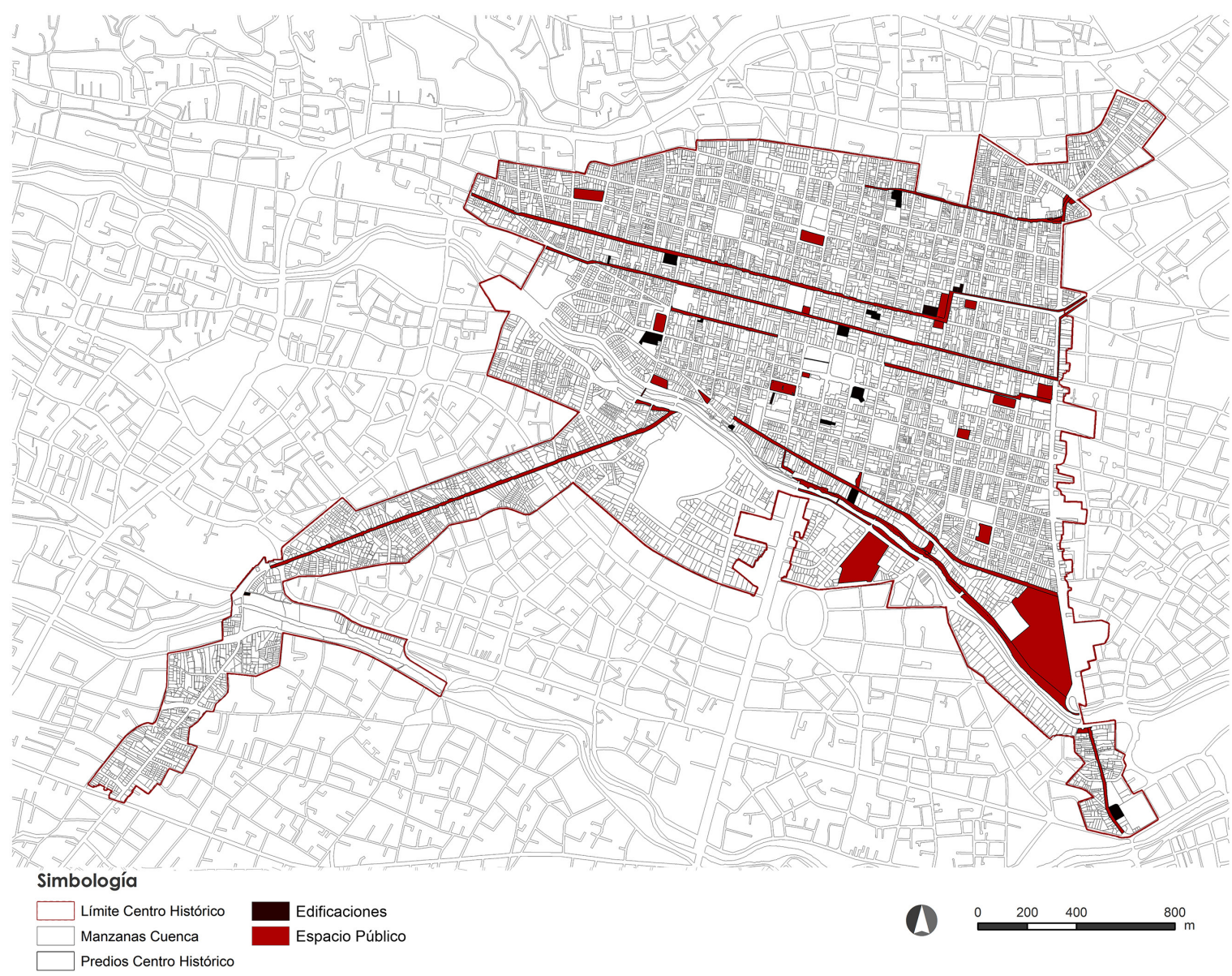

Nota: Imagen elaborada en ArcGIS

ción del patrimonio urbano y de fomento del turismo y de cuestionar aquellas estrategias de regeneración de lo público que excluyen las lógicas y estéticas populares.

\section{Agradecimientos y financiación}

La autora expresa su agradecimiento a la Universidad del Azuay, en particular al Vicerrectorado de Investigaciones por el financiamiento del proyecto "Turismo en áreas patrimoniales. El caso de Cuenca (2000-2015)". Además, agradece a los directivos de la Facultad de Diseño, Arquitectura y Arte y al Grupo de Investigación de la Escuela de Arquitectura, por su permanente apoyo.

\section{Referencias}

Barrera, J., Cabrera, L., Guerrero, L., Lazo, H., \& Pérez, I. (2008). Análisis de la evolución urbana de Cuenca. [Tesis]. Cuenca, Ecuador: Universidad de Cuenca.

Cabrera, N., \& Greene, M. (2018). Nociones de espacio urbano en la conservación del patrimonio. El caso ecuatoriano. Proceedings Intersecciones III Congreso de Investigación Interdisciplinar en Arquitectura, Diseño y Territorio, Chile, 568-576. 
Cardoso, F. (2017). El Expediente de Cuenca, 18 años después. En F. Cardoso (Ed.). Propuesta de inscripción del Centro Histórico de Cuenda Ecuador en la lista de patrimonio mundial. Edición Comentada 2017 (pp. 17-26). Cuenca, Ecuador: Universidad de Cuenca.

De la Calle, M. (2002). La ciudad histórica como destino turístico. Barcelona, España: Editorial Ariel.

Díaz, I. (2015). Perspectivas del estudio de la gentrificación en América Latina. En V. Delgadillo, I. Díaz \& L. Salinas (Coord.). Perspectivas del estudio de la gentrificación en México y América Latina (pp. 1131). México: Universidad Autónoma de México.

Fundación Municipal Turismo para Cuenca. (2011). Plan Estratégico de Desarrollo Turístico del destino Cuenca y su Área de Influencia. Cuenca, Ecuador: Fundación Municipal Turismo para Cuenca.

GAD Municipal de Cuenca. (2011). Plan de Desarrollo y Ordenamiento Territorial (PDOT) del Cantón Cuenca, 2011.Cuenca, Ecuador: GAD Municipal de Cuenca.

GAD Provincial del Azuay. (2015): Plan de Desarrollo y Ordenamiento Territorial del Azuay Actualizado, 2015-2030.Cuenca, Ecuador: GAD Provincial del Azuay.

García, M., Osorio, P, \& Pastor, L. (2017). Estudio sobre los impactos socio-económicos en Cuenca de la migración residencial de norteamericanos y europeos: aportes para una convivencia armónica. Cuenca, Informe de consultoría.

Hiernaux, D., \& González, C. (2015). Patrimonio y turismo en centros históricos de ciudades medias. ¿Imaginarios encontrados? URBS: Revista de Estudios Urbanos y Ciencias Sociales, 5(2), 111-125. Disponible en https://bit.ly/3fk7c4Z

Ilustre Municipalidad de Cuenca. (1998). Propuesta de inscripción del Centro Histórico de Cuenda Ecuador en la lista de patrimonio mundial. En F. Cardoso (Ed.). Propuesta de inscripción del Centro Histórico de Cuenda Ecuador en la lista de patrimonio mundial. Edición Comentada (pp. 37-114). Cuenca, Ecuador: Universidad de Cuenca.
Ilustre Municipalidad de Cuenca. (2009). Plan Especial del Centro Histórico de Cuenca. Documento preliminar. Cuenca, Ecuador: GAD Municipal de Cuenca.

ICOMOS. (2015). Normas de Quito (1967). ICOMOS. Disponible en

https://www.icomos.org/charters/quito.htm

Janoschka, M., Sequera, J., \& Salinas, L. (2013). Gentrificación en España y América Latina: un diálogo crítico. International Journal of Urban and Regional Research 38(2), 155-171.

https://bit.ly/3fj5ZuQ

Lefebvre, H. (1969). El derecho a la ciudad. Barcelona, España: Península.

Lefebvre, H. (1972). Espace et politique. Le droit à la ville II. París, Francia: Éditions Anthropos.

Manrique, A. (2013). Gentrificación de La Candelaria: reconfiguraciones de lugar de residencia y consumo de grupos de altos ingresos. Revista Colombiana de Geografía, 22(2), 211-234.

https://doi.org/10.15446/rcdg.v22n2.24940

Marulanda, A., \& Martí, M. (2019). Desafiando la gentrificación. Resistencias a los desplazamientos en los centros históricos de Quito y Cuenca. Scripta Nova Revista Electrónica de Geografía y Ciencias Sociales, 23(607), 1-27.

https://doi.org/10.1344/sn2019.23.21104

Matus, C. (2017). Estilos de vida e imaginarios urbanos en nuevos residentes de Lastarria y Bellas Artes: el barrio patrimonial como escenario de diversidad, distinción y movilidad. EURE. Revista Latinoamericana de Estudios Urbano Regionales, 43(129), 165-186.

https://bit.ly/3cUn6kZ

Navarrete, D. (2017). Turismo gentrificador en ciudades patrimoniales. Exclusión y transformaciones urbano-arquitectónicas del patrimonio en Guanajuato, México. Revista INVI, 32(89), 61-83. Disponible en https://bit.ly/3hpIz9a 
Osorio, K. (2012). Los atributos del Valor Universal Excepcional de una propiedad considerada Patrimonio Mundial. El caso del Sitio Arqueológico de Panamá Viejo y Distrito Histórico de Panamá. Canto Rodado, 7(1), 1-27.

Pallasma, J. (2014). La imagen corpórea. Imaginación e imaginario en la arquitectura. Barcelona, España: Editorial Gustavo Gili.

Pedersen, A. (2005). Gestión del turismo en sitios del Patrimonio Mundial: Manual práctico para administradores de sitios del Patrimonio Mundial. UNESCO. Disponible en https://bit.ly/2MWTmtq

UNESCO. (2011). What is intangible cultural heritage? París, Francia: UNESCO.

UNESCO. (2014). Indicadores Unesco de Cultura para el Desarrollo. Manual Metodológico. París, Francia: UNESCO.

UNESCO. (2017a). Ciudad de Quito. UNESCO. Disponible en https://whc.unesco.org/es/list/2

UNESCO. (2017b). Centro histórico de Santa Ana de los Ríos de Cuenca. UNESCO. Disponible en https://whc.unesco.org/es/list/863

UNESCO. (2018). World Heritage Centre. UNESCO. Disponible en http://whc.unesco.org/

Waldenfels, B. (2009). El habitar físico en el espacio. En G. Schröder y H. Breuninger (Comps.), Teoría de la Cultura. Un mapa de la cuestión (pp.157-178). Buenos Aires, Argentina: Fondo de Cultura Económica.

World Travel Awards. (2019). 2019 World Travel Awards. Disponible en https://bit.ly/2YzGuhZ

Zibell, M. (2012). Cuenca, la "ciudad prometida" para los estadounidenses. BBC Mundo. Disponible en https://n9.cl/w5go 